\title{
Complutum
}

ISSN: 1131-6993

\section{El registro arqueológico como patrimonio histórico}

\author{
Narciso Zafra de la Torre ${ }^{1}$
}

Recibido: 10 de diciembre de 2016 / Aceptado: 25 de julio de 2017

Resumen. El patrimonio arqueológico se define por su metodología y no por sus valores, en consecuencia la disciplina arqueológica y sus profesionales estamos comprometidos en su definición. Como, además, una parte de la metodología -el registro arqueológico- se ocupa de los hallazgos y su inventario, entonces determina (determinamos) el dominio público arqueológico. Mediante el dominio público arqueológico el legislador ha otorgado una protección superior al patrimonio arqueológico, al entender que está constantemente amenazado de expolio y que, por ello, debe ser retirado del mercado. Esta amenaza demuestra que el patrimonio arqueológico es un patrimonio indeseado, y por tanto no puede ser el resultado de una convención social. De lo anterior se infiere que todo el registro arqueológico es, y debe seguir siendo, patrimonio histórico.

Palabras clave: patrimonio histórico; registro arqueológico; dominio público arqueológico; metodología.

\section{[en] Archaeological Record as Archaeological Heritage}

Abstract. The archaeological heritage is defined by its methodology and not by its values, consequently archaeological discipline and its professionals are involved in their definition. In adidition, a part of the methodology - archaeological record- investigates the findings and its inventory, then determines the archaeological public domain. By archaeological public domain the legislature awarded better protection to the archaeological heritage, as long as there was not threat of plundering and therefore must be retired from market. This menace demonstrates that the archaeological heritage is an undesiderable heritage, and therefore can not be the result of a social convention. From the above it is inferred that the entire archaeological record is, and must remain, historical heritage.

Keywords: Archaeological Heritage; Archaeological Record; Archaeological Public Domain; Methodology.

Sumario. 0. Introducción. 1. El patrimonio arqueológico se define por su metodología no por sus valores. 2. El registro arqueológico determina el dominio público arqueológico. 3. El dominio público otorga una protección superior al patrimonio arqueológico. 4. El patrimonio arqueológico es un patrimonio indeseado. 5. El patrimonio arqueológico no es una convención social.

Cómo citar: Zafra de la Torre, N. (2017): El registro arqueológico como patrimonio histórico. Complutum, 28(1): 2335 .

Contra los monumentos, las ruinas Alfredo González Ruibal, 2012: “Arqueología y Memoria Histórica”

\section{Introducción}

Este texto es deudor de un comentario realizado por Álvaro Falquina Aparicio ${ }^{2}$ durante el debate de la $4^{\mathrm{a}}$ sesión de las VII Jornadas de jóvenes en investigación arqueológica. El debate se celebró en el Salón de Grados da la Facultad de Letras de la Universidad del País Vasco (Vitoria-Gasteiz), el 8 de mayo del 2014, y tenía como tema la "Arqueología de la contemporaneidad y contemporaneidad de la Arqueología". El comentario es el siguiente:

\footnotetext{
Consejería de Cultura de la Junta de Andalucía. Delegación en Jaén (España).

E-mail: narciso.zafra@juntadeandalucia.es
} 
Parece que la Arqueología trabaja con patrimonio y eso no es verdad, la Arqueología trabaja con las cosas. (...) Una jeringuilla (-localizada en una excavación-) no es patrimonio pero sí es un objeto arqueológico, (...) nosotros como arqueólogos tenemos que asumir que no trabajamos con patrimonio. (...) El patrimonio es un terreno de conflicto, porque no deja de ser una cosa que tiene una carga política en la que, de alguna manera, se materializa un enfrentamiento. (...) Un arqueólogo no es un patrimonializador.

Esta reflexión recoge el sentir y el pensar de una parte de la profesión. Quizás no me habría movido a escribir si, en parte, no coincidiera con otra concepción algo menos extremada, pero más extendida, expresada, por ejemplo, en uno de los más recientes textos sobre el ser de la Arqueología, Arqueológicas. La razón pérdida de Felipe Criado:

el patrimonio es un subconjunto privilegiado del registro arqueológico. (...) el registro arqueológico estaría formado (por ejemplo) por los útiles prehistóricos, los restos de talla o las muestras polínicas (...). Si bien es obvio que los primeros merecen per se la categoría de patrimonio arqueológico, es discutible si esta se debe aplicar a los segundos y parece un despropósito extenderla a las terceras. (...) el patrimonio arqueológico está constituido por aquellos elementos (todos, una parte o ninguno) del registro arqueológico que a través de un proceso de valoración histórica y patrimonial parezca oportuno sancionar como bienes patrimoniales. La definición de patrimonio es el resultado de una convención social (Criado 2012: 192).

Ambos párrafos contradicen el artículo 40 de la Ley 16/1985 de patrimonio histórico Español, según el cual "forman parte del patrimonio histórico Español los bienes muebles o inmuebles de carácter histórico, susceptibles de ser estudiados con metodología arqueológica, hayan sido o no extraídos y tanto si se encuentran en la superficie o en el subsuelo, en el mar territorial o en la plataforma continental". De modo que, según la definición legal, es el carácter de dato arqueológico lo que proporciona la cualidad de patrimonio al patrimonio arqueológico; no es, por tanto, el resultado de una convención social, salvo que consideremos así a las leyes emanadas de los parlamentos ${ }^{3}$. Luego son patrimonio los útiles, los debris, el polen y la jeringuilla siempre y cuando sean estudiados con metodología arqueológica. Lo que quiere decir que el patrimonio arqueológico no es un "subconjunto privilegiado" del registro arqueológico, es el propio registro arqueológico.

Evidentemente aquí hay dos concepciones del patrimonio arqueológico. Por un lado la concepción (digamos) antropológica, que defiende que este es una construcción social; y por otro la concepción legal ${ }^{4}$ que sostiene que los objetos arqueológicos son metodológicamente patrimoniales. La concepción antropológica, dominante en la última bibliografía, no tiene aún una proyección eficaz sobre la realidad del patrimonio, en tanto que la concepción legal, lógicamente, es el apoyo de todo el entramado administrativo de la gestión patrimonial. Con este texto pretendo compartir los argumentos por los que creo que la definición legal es más eficaz para garantizar la utilidad social del patrimonio. Siempre, claro está, que las administraciones puedan, sepan o quieran llevar a efecto las políticas que implica. Se parte del siguiente párrafo, que después se desarrolla:

El patrimonio arqueológico se define por su metodología y no por sus valores, en consecuencia la disciplina arqueológica y sus profesionales estamos comprometidos en su definición. Como, además, una parte de la metodología -el registro arqueológico- se ocupa de los hallazgos y su inventario, entonces determina (determinamos) el dominio público arqueológico. Mediante el dominio público arqueológico el legislador ha otorgado una protección superior al patrimonio arqueológico, al entender que está constantemente amenazado de expolio y que, por ello, debe ser retirado del mercado. Esta amenaza demuestra que el patrimonio arqueológico es un patrimonio indeseado, y por tanto no puede ser el resultado de una convención social.

\section{El patrimonio arqueológico se define por su metodología no por sus valores ${ }^{5}$}

Toda investigación arqueológica parte del diseño de un proyecto, que marca los objetivos, establece la metodología a seguir para conseguirlos, y precisa el modelo de registro a uti- 
lizar. El proyecto contiene la sistematización teórico-metodológica y la formalización de los procedimientos para generar el conocimiento arqueológico. La metodología es el conjunto de herramientas teóricas, recursos técnicos y protocolos de actuación que nos permiten realizar una intervención. En función de los objetivos, la metodología fija los procedimientos de intervención (excavación, prospección, documentación, etc.) y de obtención de datos. Estos se recogen en el registro arqueológico, que suele ser una o varias bases de datos que pueden contener la información sobre los artefactos, ecofactos, unidades sedimentarias, unidades estructurales, etc., y diversas documentaciones: gráficas, infográficas, fotográficas, cartográficas, etc.

Para poder ser estudiados con metodología arqueológica cualquier objeto debe formar parte del registro arqueológico. Por tanto, el registro arqueológico es la parte de la metodología arqueológica que observa, define y ficha los objetos arqueológicos. Recoge, identifica y ordena los bienes muebles e inmuebles a los que hace mención el artículo 40 de la Ley de patrimonio. Es decir, determina que se puede analizar con metodología arqueológica y, por tanto, que puede considerarse patrimonio arqueológico.

De modo que el patrimonio arqueológico se define por su metodología; ésta, como parte de la estructura de la investigación arqueológica, se fija en un proyecto, que solamente pueden llevarlo a cabo arqueólogas/os debidamente acreditadas/os. Luego, el patrimonio arqueológico es definido por los profesionales de la arqueología reglamentariamente autorizados. Esto es fundamental para entender el papel de la Arqueología como disciplina en la consideración jurídica del patrimonio arqueológico, rol no bien comprendido por los arqueólogos, como hemos visto, pero asumido por los juristas: "A la invención jurídica del dominio público arqueológico no puede seguir la de su objeto. Dejemos, en consecuencia, que los arqueólogos debatan acerca de la metodología de su trabajo y asumamos sus conclusiones" (Barcelona 2000: 152).

Estos debates nos han llevado primero a aplicar, en las distintas posiciones teóricas, los modelos creados desde las regiones epistemológicas de las ciencias humanas (Foucault ([1966] 1999: 334-362). Primero los modelos biológicos dominantes en la arqueología histórico-cultural (el sistema de las tres eda- des, el evolucionismo, el difusionismo); después los modelos económicos que aportan contenidos a buena parte de la arqueología espacial y a la nueva arqueología (marxismo, funcionalismo, procesualismo); y finalmente los lingüísticos que dominan en la arqueología del paisaje y en la post-procesual (teoría de sistemas, estructuralismo, neo-marxismo, neo-historicismo) (Zafra 2004: 26). En estos procesos de investigación intervienen instancias ideológicas y metodológicas (Bate 1998: 147-176). Entre estas últimas, la producción de información y concretamente el sistema de registro, se ha visto modificado por los distintos posicionamientos teórico-metodológicos. Así, a los artefactos (productos), se han sumado los arteusos (deshechos), a estos los circundatos (muestras) (Lull 1988: 64), y desde los años 80 del siglo XX, se observa un creciente interés por los aspectos simbólicos del registro material. Esto incide en los sistemas de registro de, por ejemplo, la Arqueología del Paisaje, que se orientan a trascender las limitaciones que la materialidad del registro arqueológico impone a los estudios históricos (Soler 2007: 43).

El registro arqueológico es una peculiar herramienta metodológica puesto que es el objeto observado y, a la vez, el resultado de la observación. Consideramos registro tanto al material como a los datos asociados con que lo fichamos. Esto es así porque un objeto por si mismo no posee los rasgos que lo hacen arqueológico si no va acompañado de determinada información: procedencia y contexto principalmente. Cualquier elemento de prueba arqueológica requiere del concurso del objeto y de la información aneja que lo identifica $^{6}$.

El registro es selectivo e interpretativo dependiendo de la información empírica, de los objetivos del proyecto y de la base teórica del investigador (Bate 1998: 151). El registro no se recupera se elabora, por tanto, no depende solo de la destreza técnica del equipo investigador, sino de las preguntas que, desde sus planteamientos teóricos, le hace al objeto de estudio. De manera que desde que la Ley se promulgó, en 1985, el campo de lo que puede ser estudiado con metodología arqueológica se ha ampliado. Hoy la Arqueología investiga todas las etapas históricas, desde el presente hasta la paleolitización, y todas las dimensiones del espacio: la física, la socio-económica y la simbólica. Evidentemente en la mentali- 
dad de los legisladores estaba la concepción del método arqueológico de su tiempo ${ }^{7}$ y en función de esta, protegieron los objetos y restos materiales, tanto los excavados como los potenciales, fruto de las prospecciones ("hayan sido o no extraídos" dice el artículo 40 de la Ley). Pero no sospecharon que la arqueología se propondría estudiar algo tan poco material como la dimensión simbólica del paisaje. Así que esta, lamentablemente, se encuentra fuera de la definición de patrimonio vigente, que "solo" protege bienes inmuebles, muebles, objetos y restos materiales, pero no así los "efectos e indicios" que los rodean, ni el "reflejo de sus consecuencias" (Criado 2001: 39).

Como señala Vicent (2007: 341) la separación de los conceptos 'registro arqueológico' y 'patrimonio', asimilado el primero con el valor científico y el segundo con el monumental, nos remite a la noción franquista del patrimonio. La interpretación neoliberal es semejante. Las políticas apoyadas en estas interpretaciones, junto con la consideración de los objetos arqueológicos como meros productos, son la base de la estrategia de mercantilización del patrimonio. Ahora, la retórica del desarro1lo, la propiedad individual y la libre empresa marcan las metas a los nuevos cuerpos legislativos (Giovannetti y Páez 2009: 92), librando al mercado de cortapisas. Limitaciones que imponía y aún impone la concepción legal, de base socialdemócrata, apoyada forzosamente en los especialistas que deben resolver sobre la metodología. La concepción antropológica es, sin embargo, conservadora, pues, en el fondo, solamente considera patrimonio aquellos bienes que gozan de suficientes defensores, que por sí mismos pueden alentar su consideración social. Y así, mientras se hace pivotar la protección y consideración patrimonial en la sociedad civil, estamos librando al Estado de la responsabilidad y el costo de esta carga, y así el patrimonio inmaterial, precisamente por no necesitar inversiones ni afectar a las propiedades, es preferido por las políticas neoliberales.

Para la concepción antropológica, es patrimonio arqueológico solamente aquella parte del registro que se ha puesto en valor o es susceptible de ponerse en valor. Es decir aquellos materiales o sitios arqueológicos que han logrado pasar todos los filtros de la cadena de valoración del patrimonio arqueológico (Criado 1996; Barreiro 2013) y han sido con- vertidos en patrimonio musealizado o, más correctamente si seguimos a Barreiro (2013: 213), en patrimonio socializado. Generalmente son pruebas de valoración científica, técnica y política a los que se somete el inmenso acervo que conforma la historia material. Sabemos que, para la Arqueología, la Historia es una catástrofe única: la suma de las ruinas de lo que no ha resistido, de los despojos de los que no han sobrevivido. Tradicionalmente de ese inmenso conjunto, que forma parte de la misma tierra, se han destacado determinados hitos por valorarlos artísticos o monumentales, despreciando el resto. De modo que, generalmente, se preserva para futuras generaciones el castillo del noble y no la aldea de los campesinos, el templo del sacerdote y no el caserío de los parroquianos, el palacio del gobierno y no la edilicia de los súbditos, o la gran arquitectura fabril y no los barracones de los obreros. Por este mecanismo, aparentemente natural, de reconocer y apreciar lo artístico o lo monumental -vale decir lo bello o lo espectacular-, obtenemos una visión sesgada, manipulada y por ello falsa de la Historia, porque el castillo, el palacio, la iglesia o la fábrica no se explican sin las aldeas, el caserío, la edilicia o los barracones.

Por el mismo tipo de tamiz hacemos pasar al registro arqueológico si aceptamos la concepción de patrimonio según la cual son patrimonio los artefactos, lo pueden ser los restos de talla y no lo son las muestras. Donde los valores que se destacan son la integridad, dado que la clasificación del material y su estado de conservación son determinantes de cara a su musealización; y la representatividad, dado que es su grado de relación con los receptores previstos lo que le otorga la consideración social. Sin embargo, para su fundamentación como patrimonio arqueológico, no importa que tal objeto sea monumental o artístico, sea de tal periodo o estilo, o esté más o menos íntegro, ni siquiera que sea educativo o socialmente rentable, solo importa que pueda ser estudiado por métodos arqueológicos, esto es, que sea un documento arqueológico. Y aquí interviene el profesional de la arqueología como la instancia que puede y debe decidir sobre que es y que no es arqueológico, sobre que es y que no es patrimonio. De su decisión se desprenden importantes consecuencias jurídicas, pues además de catalogarlos como patrimonio, los objetos arqueológicos pasan a formar parte del dominio público. 


\section{El registro arqueológico determina el do- minio público arqueológico}

La ciencia arqueológica se puede definir como el proceso de producción de registro arqueológico (Vicent 2007: 330). Este, como se ha dicho, es la parte de la metodología que inventaría (recoge, observa, define, identifica, ordena y ficha) los bienes arqueológicos, que, por su mediación, pasan a ser bienes patrimoniales. El registro arqueológico es el instrumento metodológico que autentifica el hallazgo, lo convierte en patrimonio arqueológico y lo transmuta en dominio público. Pero vayamos por partes.

El proyecto arqueológico permite a la administración evaluar la idoneidad de lo planteado, autorizarlo e inspeccionar si lo autorizado se cumple. El registro arqueológico, como parte del proyecto, tiene entre sus funciones la de garantizar el valor como prueba que poseen los restos arqueológicos. El registro es garante de la autenticidad del bien, probando mediante el examen de la cadena de custodia, avalada por la deontología del arqueólogo/a y las funciones del inspector/a nombrado por la administración, que cualquier objeto (una cerámica, una semilla, un estrato, una estructura, etc.) que se utiliza como prueba en favor de su adscripción cronológica o funcional, de su peritaje judicial, de su valoración social o de su tasación económica ${ }^{8}$, procede efectivamente de la intervención autorizada.

En efecto, la inclusión en el registro le otorga cierta seguridad jurídica y por ello al carácter histórico de cualquier objeto extraído en una investigación arqueológica, se une la dimensión jurídica de su autenticidad. Para demostrarla no basta con que el estudio sea solvente y metodológicamente intachable, sino que también debe estar supervisado legalmente por la administración patrimonial. Y no por un mero afán controlador, sino por ser la garante de la cadena de custodia del registro arqueológico, ya que, a la vez, este se convierte en dominio público. Esto puede no gustar a los profesionales, pero añade al procedimiento un plus de seguridad jurídica necesario por el papel que la legislación otorga a la metodología arqueológica: (insisto) creadora de patrimonio histórico y de dominio público.

Es una característica jurídica del registro arqueológico que los objetos listados en él, sean arquitecturas, cerámicas o pólenes, en tanto fruto de la metodología arqueológica son demaniales. Puesto que "forman parte del patrimonio histórico Español los bienes muebles e inmuebles de carácter histórico, susceptibles de ser estudiados con metodología arqueológica" (Artículo 40.1 de la Ley 16/1985 de patrimonio histórico Español); y "son bienes de dominio público todos los objetos y restos materiales que posean los valores que son propios del patrimonio histórico Español y sean descubiertos como consecuencia de excavaciones, remociones de tierra u obras de cualquier índole o por azar" (Artículo 44.1 de la misma Ley).

Puede pensarse que el artículo se redactó para los objetos arqueológicos que se extraían de una excavación, cuyo destino final es el museo, pero no para los vestigios constructivos. El profesor Barcelona (2000: 155) dice que "el dominio público arqueológico se circunscribe a los objetos, no a su nicho natural". Para ser exactos la Ley dice "los objetos y restos materiales" (Artículo 44.1 de la Ley 16/1985), lo que lógicamente no se refiere a su "nicho natural", pero no se circunscribe a los objetos. Convenimos con el profesor Barcelona, en que todo el espacio recipiente de los objetos arqueológicos no debemos considerarlo demanial, pero ¿Qué ocurre con las estructuras? Solo a ellas se podía referir el legislador cuando menciona, distinguiéndolos de los "objetos", a los "restos materiales", pues estos son los vestigios, residuos o ruinas de construcciones. Luego los edificios y sus partes son también dominio público, "siempre y cuando sean descubiertos por excavaciones, remociones de tierra u obras de cualquier índole o por azar". Es decir siempre y cuando estén soterrados. No parece que tengamos que esforzarnos para demostrarlo cuando se trata de un mosaico romano (aunque los propietarios del terreno superficial intenten probar lo contrario, como en el caso conquense de la impresionante villa de Noheda), pero será más complicado ante un suelo de ocupación neolítico, sin embargo en ambos casos son dominio público. Cosa distinta es que, llegado el caso, el Estado deba indemnizar por la superficie. Por tanto el dominio público arqueológico hace referencia a los bienes muebles e inmuebles. Opinión compartida por el Tribunal Supremo para el cual, el dominio público incluye los bienes inmuebles pues, aunque no ha tratado claramente si el artículo 44.1 de la Ley 16/1985 alcanza a estos bienes, su jurisprudencia se inclina por asumir el carácter demanial de los mismos (Moreu 2013: 246-247). 


\section{EI dominio público otorga una protección superior al patrimonio arqueológico}

Según el Art. 132.2 de la Constitución "son bienes de dominio público estatal los que determine la ley y, en todo caso, la zona marítimo-terrestre, las playas, el mar territorial y los recursos naturales de la zona económica y la plataforma continental". Uno de los determinados por ley es el patrimonio arqueológico (Art. 44.1 de la Ley 16/1985). Son bienes destinados al uso o servicio público, y por ello, son inalienables, imprescriptibles e inembargables, esto es: están excluidos del comercio, sus derechos no caducan, y no se pueden embargar. ¿Por qué, a diferencia del resto de bienes del patrimonio histórico, los bienes arqueológicos son de dominio público, cuando cumplen la misma función social y portan el mismo valor cultural que los demás? Los juristas han propuesto dos causas: la primera sostiene que, la razón de ser del dominio público arqueológico, es impedir que los particulares puedan acceder a la propiedad de bienes arqueológicos (Alegre 1994: 365 y ss); la segunda propugna que se encuentra en la voluntad de otorgarle una protección especial y superior ante la fragilidad y el desamparo que muestra frente al expolio (Barcelona 2000: 138 y ss).

Juan Vicent (2007: 331), en un inspirado texto sobre la arqueología a comienzos del siglo XXI, menciona los tres tipos de valor que dan forma al registro arqueológico: los valores cognoscitivos en tanto objeto de conocimiento; los patrimoniales en cuanto a objeto de derechos ciudadanos y deberes del Estado; y finalmente los económicos. Los efectos de estos últimos son los que motivan su consideración como dominio público. Los valores económicos conforman un prisma de varias facetas. Por un lado, los vestigios arqueológicos forman parte del suelo, y el suelo tiene un valor en el mercado inmobiliario. Por otro lado, la marca "patrimonio" (cuya máxima expresión nacional es la catalogación como Bien de Interés Cultural, e internacional la declaración de Patrimonio Mundial) es generadora de turismo cultural, cuyo valor se incrementa con la monumentalidad y espectacularidad. Finalmente, en cuanto objetos tienen valor por si mismos, no solo por el material en que están fabricados, sino por su antigüedad en el mercado anticuario legal e ilegal. Estos tres tipos de valor de cambio ocasionan daños al patrimonio arqueológico mediante varias vías: expolio por obras que implica la desaparición de los vestigios y de su contexto, por detectores que suponen su extracción incontrolada y venta ilegal; y fraude por adulteración que afecta a su autenticidad.

El mercado inmobiliario y la catalogación arqueológica litigan por la consagración del suelo a la especulación o al patrimonio. Gilles Deleuze (1980: 49) decía que la diferencia entre los demonios y los dioses estriba en que estos tienen atributos, propiedades y funciones fijas: tienen que ver con los suelos, las lindes y los catastros; lo propio de los demonios, por el contrario, es saltar los intervalos y de un intervalo a otro. En este sentido las catalogaciones patrimoniales son demoníacas porque transgreden los sacrosantos límites de la propiedad, verdadero Dios en este mundo sin tierras de nadie. Esto no es, ni mucho menos, así, pero se percibe de este modo, especialmente, con el dominio público arqueológico. Pero se puede dar la vuelta al argumento, afirmando que las catalogaciones arqueológicas se convierten en una especie de sacramento cívico, que busca marcar la tierra como inhábil para cualquier uso que no sea su consagración al servicio del patrimonio. Se alcanza esta "sacralidad" mediante una ley, un decreto, una orden o una resolución, al igual que el suelo consagrado en la antigua Roma que alcanzaba tal estatus en virtud de un senatusconsulto. En Roma, las "cosas santas" (las murallas, las puertas o los templos) no podían ser de nadie, en España, desde 1985, el patrimonio arqueológico tampoco. Sin embargo ningún dominio público resiste el envite de los miles de millones euros que, como un tsunami, se abatieron sobre nuestro suelo. Ni las playas, ni los ríos, ni las carreteras, ni, por supuesto, el patrimonio arqueológico, pudieron frenar la bolsa especulativa $y$, de aquellas alegrías para la profesión, estas tristezas para la disciplina.

Con la actual legislación, desde 1985, los hallazgos arqueológicos posteriores a esta fecha no son mercancías. Luego la única manera de comercializarlos es mintiendo sobre su origen (haciendo su descubrimiento anterior a 1985 o de procedencia extranjera), o directamente, en el mercado negro. Existen redes que trafican con bienes arqueológicos que consiguen documentación falsa, y gracias a ella, se insertan en el mercado de antigüedades legal. Pero el tráfico más generalizado es el que se organiza a través del mercado negro. Son redes que necesitan a los detectoristas, que obtienen las piezas de los yacimientos arqueológicos, 
a los intermediarios que las hacen circular, y a los coleccionistas que son los destinatarios finales. Todo tiempo es propicio para su funcionamiento: cuando la economía va bien, hay un mercado de objetos arqueológicos en alza y dinero para gastar; cuando va mal, la afición al detector crece, viendo en ella un complemento a los ingresos, aumentando la cantidad de bienes en circulación. Estas redes se nutren de yacimientos sin protección efectiva, que son la mayoría de los españoles. Pero el mercado negro internacional aprovecha fisuras en las legislaciones nacionales y, especialmente, en las regiones con conflictos bélicos, para organizar un saqueo sistemático e impune. Aprovechando la opacidad de la que hacen bandera, estas redes también ponen en circulación falsificaciones arqueológicas, en los mismos circuitos (pitero-intermediario-coleccionista) que son los que dan apariencia de autenticidad a las piezas, uniendo el fraude al expolio.

La industria turístico-cultural, por su parte, incide contra el patrimonio imponiendo una monumentalidad y espectacularidad que, en demasiadas ocasiones, no responde a la verdad. Debemos a esta industria y a los políticos que, sin asesoramiento adecuado, la alientan y financian, el sinfín de castillos sobre-restaurados o yacimientos hiper-reconstruidos, sometidos a un tratamiento "valiente", con materiales "punteros" y técnicas "vanguardistas", que hay dispersos por el país. También inducen a provocar daños por la adulteración de las reconstrucciones. Por ejemplo, se puede convertir un espacio banal en uno significativo, como ha ocurrido con la supuesta sinagoga del agua en Úbeda, donde la ausencia de registro arqueológico evidencia que los datos utilizados para defender su adscripción crono-cultural como aljama medieval, son insuficientes, acientíficos, discutibles e inciertos, y en todo caso no son válidos para autentificar la fingida sinagoga. Hay otra adulteración motivada por los plazos de obra y la ausencia de sensibilidad, que atañe al propio registro arqueológico, ninguneado en el caso del museo de Baeza, donde disponiendo de los resultados de varias campañas de excavación, no se consideraron en absoluto en el discurso museográfico, distribuyendo los materiales sin contexto, montando un museo del siglo XIX en pleno siglo XXI. Estos dos ejemplos se producen en sendas ciudades patrimonio de la Humanidad, donde los réditos económicos pesan más que cualquier afán patrimonial. ¿Cómo impedir que la autenticidad se interponga entre la empresa turística y su cliente? Si hay "bachilleres y pedantes" que murmuren de la supuesta verdad que trasmiten, la ignorancia prescribe ignorarlos.

El valor de cambio, en sus diversas facetas, impone el objeto (arqueológico, monumental, etc.) y su "marca" (romano, antiguo, histórico, etc.) como producto, y sitúa su gestión, lógicamente, en el dominio de la propiedad y la adquisición; el patrimonio arqueológico, por su parte, se basa en el método y la autenticidad y se acomoda en el dominio del uso y la transmisión. En realidad no es la oposición entre lo privado y lo público sino entre lo propio y lo ajeno la que sentencia en la disputa. Es este valor de mercado, legal e ilegal, lo que estimula el expolio y la adulteración, por eso la sobre-protección otorgada por el dominio público es tan necesaria. Pero sorprendentemente para la posición antropológica, de lo que debe protegerse es de la acción de los propios ciudadanos, pues la inercia del sistema empuja hacia el dominio absoluto de la propiedad y la adquisición. La legislación patrimonial se resiste a abandonar los valores patrimoniales en manos del mercado, pero este, todopoderoso, deja pocas cosas fuera de su influjo.

\section{El patrimonio arqueológico es un patrimonio indeseado}

Si se admite que el patrimonio histórico incuestionado, el de las oligarquías y el Estado (los monumentos), se debe a "la fatiga de los grandes genios que lo han creado y a la esclavitud sin nombre de sus contemporáneos" (Benjamin 1971: 81), cuando prescindimos de la primera, como ocurre generalmente con el patrimonio arqueológico, en su inmensa mayor parte restos de la cotidianidad (las ruinas), sólo se hace evidente el sufrimiento, la "esclavitud", $\mathrm{y}$ ese es un patrimonio que nadie quiere heredar, con el que nadie quiere identificarse y que incomoda a las conciencias mas tradicionales, que sólo con fuerza están dispuestas a admitir su valor cultural. Si algunos de estos grandes monumentos como la iglesia de Santo Domingo en Alcalá la Real, la de San Miguel en Jaén o el Puente Ariza en Úbeda, sin salir de la provincia de Jaén, están seriamente amenazados desde hace años, poco futuro vemos para las ruinas arqueológicas como la necrópolis del Pozo del Vélez en Porcuna, el estanque de la Alamedilla en Arjona, o la villa de Casablan- 
ca en Linares por poner tres ejemplos también giennenses. Lamentablemente es cierta la demoledora observación de Criado (2001: 40) sobre la situación del patrimonio en España: "la conciencia ciudadana es poco menos que nula, el dinero invertido insuficiente, (y) el celo de los profesionales implicados no palia las deficiencias anteriores".

Nuestra experiencia nos empuja a darle la razón. En demasiadas ocasiones en los conflictos patrimoniales una buena parte de la población se opone o es indiferente a la conservación. ¿Como actuar? Criado propone "aceptar que el derecho de todo lo que existe (sea criatura viva o no) es seguir existiendo" (2013: 12), como esto presenta enormes dificultades que no se le escapan, asume que para resolver este dilema "no queda más remedio que acudir a instancias de legitimación externas (p.e. la autoridad intelectual)" $\mathrm{y}$, a la vez, proponiendo el desarrollo de prácticas discursivas más sociales y comunitarias. O sea, volvemos al punto de partida. Hace 70 años la UNESCO estimó que "la más segura garantía existente para conservar los monumentos y obras del pasado reside en el respeto y estimación que por ellas sientan los pueblos", pero conscientes de que "el respeto y la estimación" no se consiguen sin acicates, afirmó seguidamente: "esos sentimientos pueden estimularse en gran parte mediante una acción apropiada inspirada por la voluntad de los Estados Miembros de desarrollar la ciencia" (Cabeza y Simonetti 1997:57). Evidentemente la ciencia, en este caso la arqueología, jugaba un papel clave en 1956 y lo sigue jugando hoy, como correa de transmisión de los conocimientos que vamos adquiriendo. Coincido con Cabello (1988: 235) en que "Indefectiblemente, respeto y amor al patrimonio histórico son directamente proporcionales al grado de cultura y educación de un pueblo. Y solo a través de la potenciación de estos dos pilares esenciales podemos quitar protagonismo a las medidas represivas". Pero, a pesar de que se dispusiera de una ciudadanía respetuosa y educada, la única manera de asegurar cierta protección al patrimonio sería mediante la Ley.

En Jaén desde 1985 la Consejería de Cultura ha incluido en la Base de Datos del patrimonio histórico Andaluz 2.474 bienes arqueológicos, de estos se han declarado Bien de Interés Cultural 437; de ellos dos se han puesto a disposición plena de la ciudadanía (Cástulo en Linares y, desde 2016, Puente Tablas en Jaén); y se ha institucionalizado uno (el Con- junto Arqueológico de Cástulo). Es un pobre bagaje para 30 años de gestión. Pero si observamos los datos no falta iniciativa, ni trabajo. Se aprecia que es en la fase de puesta en valor e institucionalización donde falta empuje, y eso es un fallo político, pues la conservación, revalorización e institucionalización, solo se ejecutan en lugares señalados políticamente.

En cuanto al celo de los profesionales se ve cotidianamente aplastado por la realidad administrativa, que, para Andalucía, se puede resumir en el editorial del $\mathrm{N}^{\mathrm{o}} 6$ de Menga - Revista de Prehistoria de Andalucía, donde se muestra una visión general del estado de la gestión arqueológica en Andalucía. En resumen, los recortes implican que apenas hay inversión en investigación, en protección, en catalogación o en conservación; que se sostienen a duras penas las partidas de gasto de personal y mantenimiento en conjuntos arqueológicos, y que los enclaves, en el mejor de los casos, se están alimentando de inversiones de organismos locales. Es más, la no provincialización de los presupuestos ocasiona que no se sepa ni cuanto ni cuando se puede gastar, incertidumbre letal para cualquier planificación. Ante esto, el esfuerzo principal se dedica a mantener en marcha los procedimientos de autorización de actividades arqueológicas. La situación no acaba de precipitar en colapso porque se mantiene en funcionamiento el sistema de protección, debido a las cautelas legales que amparan al patrimonio Arqueológico, precisamente por ser dominio público.

Por tanto ni el pueblo, ni los políticos, ni los profesionales queremos, podemos o sabemos protegerlo y conservarlo, ante esto es evidente que el patrimonio arqueológico es un patrimonio indeseado.

\section{El patrimonio arqueológico no es una convención social}

Los procesos de convención social sobre patrimonio se cruzan a menudo con la memoria. Pero la arqueología y la memoria son antitéticas, como lo son el olvido y el recuerdo. La Arqueología redime del olvido a lo olvidado, corrige, alimenta e ilustra a la historia; la memoria pretende ser un presente eterno, anula a la historia. La Arqueología es Historia la memoria no. El patrimonio arqueológico es historia material desechada, indeseada que, tras su rescate, se convierte en un patrimonio histó- 
rico mayoritariamente indeseado por la sociedad (como tal patrimonio) y codiciado por el mercado (como producto de lujo en el mejor de los casos).

En sociedades como la nuestra, pretendidamente dirigida por una determinada imagen de su propio futuro -por ejemplo evidenciada y plasmada año a año en los presupuestos generales del Estado-, el valor normativo del pasado -la evidencia de que somos lo que somos por venir de donde venimos- y su materialización -el patrimonio- queda diluida en la imposición ideológica de que somos lo que somos porque vamos a donde vamos: la comunidad de destino de Otto Bauer, convertida por José Antonio Primo de Rivera en la unidad de destino en lo universal. Lo que implica una exigencia de negación de toda historia, y con ella de todo patrimonio, que no sirva a la justificación del presente -siempre entendido como proyecto de futuro ya planificado ${ }^{10}$ - señalando a esa historia como intrínsecamente vergonzante y vetando su acceso a la consideración de patrimonio y de paso despreciando su estudio, conservación y socialización.

Un ejemplo valdría para demostrar la eficacia de estas (inconscientes) políticas de encubrimiento y confusión: la ausencia de material postmedieval en los museos arqueológicos. ¿Por qué en el siglo XXI ningún museo provincial los coloca en sus vitrinas, estando sus almacenes llenos de ellos gracias a la arqueología urbana? Esta carencia rompe el discurso histórico completo que haría comprender la relación de los tiempos actuales con los históricos. De nuevo Benjamin (1994: 186) nos da la clave en la Tesis 12 de Filosofía de la Historia, cuando anota que la clase trabajadora ha quedado relegada al papel de "redentora de las generaciones futuras", y ha olvidado que el "odio y la voluntad de sacrificio", alimentados por la imagen de los ancestros esclavizados, es lo que la convierte en vengadora de las generaciones vencidas. Pero ¿donde encontramos esta imagen capaz de reconstruir el relato unitario, interesada en el cambio y el conflicto? Desde luego no en nuestras instituciones culturales, dominadas por el Discurso Patrimonial Autorizado $^{11}$, ni desgraciadamente tampoco se adivina en los nuevos patrimonios culturales, pues en su mayoría solamente son manifestaciones de una cierta sensibilidad popular dirigida por los medios, cuando no tradiciones recién inventadas $^{12}$. Esa imagen sólo podríamos encontrarla en la Historia, que no es, en ningún caso, memoria, sino juicio y sentencia. Sin embargo las funciones del patrimonio histórico son vincular y deslumbrar, que fueron en su día las funciones naturales de las historiografías medievales de las res gestae (Foucault 1992: 76), de manera que el patrimonio, como aquellas, proporciona una visión sesgada, manipulada $y$, por ello, falsa de la Historia.

Nuestro Estado encomienda al patrimonio histórico la siguiente misión: ser el "principal testigo de la contribución histórica de los españoles a la civilización universal". De modo que estos bienes devienen patrimoniales por su función social: que los ciudadanos puedan "contemplar y disfrutar las obras que son herencia de la capacidad colectiva de un pueblo". Pero ¿como se seleccionan? Por el "aprecio con que los mismos ciudadanos los han ido revalorizando". Y esta revalorización ¿como la alcanzan? Mediante "la estima que, como elemento de identidad cultural, merece a la sensibilidad de los ciudadanos" (todos los entrecomillados de este párrafo provienen del Preámbulo de la Ley 16/1985). Sin embargo la Ley 16/1985 no contiene instrumentos de participación ciudadana en los procesos y procedimientos de declaración patrimonial. Solamente si se trata de Bienes de Interés Cultural, se otorga a la ciudadanía, compartida, la capacidad de proponerlo, más como primera instancia, pues el "organismo competente" decidirá si procede la petición (Art. 10). De modo que la participación ciudadana es casi retórica, contenida en el preámbulo pero no sustanciada en el cuerpo normativo de la Ley.

Los bienes portadores de "identidad cultural" son valorados (por el "organismo competente") como patrimonio por ser la parte de la Historia con la que, según el Estado, contribuimos a la civilización universal. De modo que la "capacidad colectiva" de nuestro pueblo se ha materializado en realizaciones excepcionales que adornan el territorio o se muestran y guardan en diversas instituciones (museos, iglesias, archivos, bibliotecas...): literaturas, pinturas, esculturas, monumentos, hazañas, tratados, reliquias, milagros, etc. Seríamos según esto, un pueblo de poetas, de artistas, de héroes, de santos, de pensadores, de científicos y de navegantes ${ }^{13}$. No seríamos, por tanto, un pueblo de campesinos, ni de oficinistas, ni de dependientes, ni de soldados, ni de comerciantes; ni, por supuesto, de amas de casa, de enfermeras, de maestras, de lavanderas, de sirvientas, de profesoras o de costureras. Con lo que el ca- 
lificativo "colectivo" que atribuyen a nuestra "capacidad" como pueblo, se ve negado por la realidad de las colosales individualidades que jalonan nuestra Historia, cuyas obras elevamos a los altares del patrimonio: Cervantes, Lorca, Velazquez, Picasso, Alonso Cano, Benlliure, Herrera, Gaudí, etc.

No obstante si la consideración de los bienes patrimoniales se hubiera conseguido por convenio y no por imposición de los "organismos competentes", no creo que los catálogos hubieran sido muy distintos de los actuales, a excepción, lógicamente, de los bienes arqueológicos, que tendrían una presencia muy minoritaria. Porque solo lo excepcional se valora y, desde un punto de vista (digamos) tradicional, lo excepcional tiene un "pequeño" hándicap: es nacionalista, imperialista, colonialista, elitista, triunfalista, racista, machista y clasista, y está dirigido por el "fetichismo del conocimiento experto", como se señala en el Manifiesto de Gothenburg ${ }^{14}$. Difícilmente encajan aquí realizaciones que no engrandezcan o embellezcan a la nación. Si aceptamos que "la historia es la memoria de los Estados", como postulaba Henry Kissinger en $A$ world restored (citado por Zinn 2011: 17), y si, como tal memoria (de los vencedores en todo tiempo), pretende instaurarse como presente eterno, intentando recuperar el "tiempo indiferenciado de los héroes, de los orígenes y de los mitos" (Nora 1984: XVIII); entonces tendremos que tragar con esa clase de interpretaciones, porque "la memoria de los estados" no se nutre de las investigaciones históricas, sino de las mitologías y tradiciones nacionales, apoyadas en estudios tendenciosos, amplificados por los mass media, que se transforman en herencia colectiva, cuyo mejor propagandista hoy es el patrimonio. Luego el patrimonio viene a reflejar la memoria de los vencedores, o lo que es igual, la Historia Oficial expresada mediante el Discurso Patrimonial Autorizado.

Pero hay un tipo de patrimonio que podría escapar a este destino: el arqueológico, que se define legalmente, como hemos visto, por su metodología. Y la metodología arqueológica se caracteriza por no hacer distingos entre los hallazgos (monumentales, artísticos, selectos, banales, de vencedores o de vencidos), homogeneizándolos como documentos arqueológicos. Estos, desde el polen al paisaje, sirven para producir conocimiento arqueológico e histórico, y son identificados, documentados, significados, evaluados, valorados, conser- vados y socializados por los arqueólogos/as. Todas estas acciones conforman la Cadena de Valor del patrimonio Arqueológico (Barreiro 2013: 205-214), y lógicamente se deben llevar a cabo por profesionales cualificados. Difícilmente podrían ser objeto de iniciativas populares o consensos sociales. Naturalmente el apoyo social es fundamental, pero sumado a la base técnico-científica, a la propuesta arqueológica que, en casi todas las ocasiones, serviría de banderín de enganche, para apoyar iniciativas de investigación, conservación y socialización.

Por el contrario, los planteamientos de quienes defienden que el patrimonio arqueológico es una construcción social, no tienen en cuenta criterios que son claves a la hora de decidir sobre que se conserva, porqué y para qué. Como hemos visto, la antropología del patrimonio ha considerado uno de los criterios de estimación del valor de conservación ${ }^{15}$, al que he denominado criterio de representatividad, como el criterio absoluto, no ya en la conservación del patrimonio sino en su definición. Este criterio de representatividad se mide por el grado de relación del patrimonio con sus receptores previstos (Zafra 1996: 235), de este modo todo el patrimonio es inmaterial porque implica un proceso de valoración social (Laurajene Smith en Sánchez-Carretero 2012: 196), que, en última instancia, depende de la capacidad del bien patrimonial para hacerse reconocer sin intermediarios. Se obvian otros criterios que informan sobre el valor de conservación, como el de diversidad, rareza, singularidad, integridad, ejemplaridad, complejidad, etc. (Zafra 1996: 235), que son cualidades que hacen patrimonio al patrimonio y que solo se pueden observar con metodología científica y perspectiva técnica.

Si en nuestra sociedad existe un modo de relación con el pasado, este no es la historia sino el patrimonio que, poco a poco, va subsumiendo a la memoria, la mitología y la tradición, acaparando todos los aspectos de la cultura: monumentos, personajes, museos, archivos, símbolos, lemas, acontecimientos e instituciones ${ }^{16}$. Los especialistas debemos expurgar y organizar, si nos dejan, este batiburrillo, que, en realidad, se asemeja al contenido de los gabinetes de curiosidades, y que presenta el mismo peligro que se advertía en aquellos: todo cabe. Así, en los vetustos gabinetes, junto a un caparazón de tortuga, una crátera griega o un arpón ballenero, no era raro encontrar san- 
gre de dragón y esqueletos de sirenas. Como muestra de que no es exageración, basten con los ejemplos que a continuación expongo: la Unión Europea, la Diputación Provincial de Jaén y el Ayuntamiento de Belmez de la Moraleda han invertido $850.000 €$ en un Centro de Interpretación de las Caras de Belmez, fenómeno paranormal famoso en las postrimerías del franquismo, que fue inaugurado el 25 de febrero de $2013^{17}$; un grupo de arquitectos de la Escuela de Arquitectura de Málaga y de la Politécnica de Cataluña proponen considerar patrimonio los productos culturales del turismo de sol y playa en la Costa del Sol (García-Moreno et al. 2016, idea interesante como ejercicio crítico, pero chocante por antipática, pues es esa cultura del ocio, del crecimiento urbano y del espectáculo, la que ha destruido el patrimonio histórico y ambiental de nuestras costas; Criado (2013: 10) trae a colación un OVNI grabado por un vándalo junto a los petroglifos de Yerbas Buenas (San Pedro de Atacama, Chile), que es, a la vez que un atentado patrimonial, una resignificación del conjunto rupestre, otorgándole una nueva racionalidad; y el Ministro de Educación y Cultura del gobierno de España ha propuesto a la Directora General de la UNESCO que las tapas sean patrimonio de la humanidad (diario El País, 31 de mayo de 2016). Ante esto ¿Para cuando la declaración como patrimonio del aire de una tarde de victoria en el estadio del Betis?

Si todo es patrimonio nada lo es, y aquí se ve un objetivo: la mercantilización por bana- lización. A la vez, decidir que la arqueología no trabaja con patrimonio, o que solo es patrimonio arqueológico lo que por convención social se categoriza como tal, es darle alas a los que, por ahora, ningunean la ley pero pronto abogarán por la desregulación, persiguiendo el mismo objetivo: convertir el patrimonio arqueológico en producto. Se que ni Álvaro Falquina ni Felipe Criado pretenden esto, solo los he utilizado como ejemplo de un pensamiento que creo equivocado, pero en un entorno legal sobreprotector con la propiedad privada es temerario darle armas al enemigo.

Como en este caso las modas intelectuales y los intereses políticos van de la mano, me temo que remo contracorriente, y por eso no espero gran cosa de esta contribución. Sin embargo, quiero hacer notar que nuestra metodología es un arma poderosa, tan poderosa que, remedando al rey Midas, todo lo que toca se convierte en patrimonio, y esa es una herramienta a la que no tenemos que renunciar. Si dejamos que el patrimonio nos venga impuesto, por los aparatos del Estado ${ }^{18}$, las clases privilegiadas, los mass media o las modas disciplinares, no podremos disputarles los discursos hegemónicos, y entonces la arqueología perdería la función que la hace, para mí, más valiosa: la de dar voz y presencia a lo que nunca la ha tenido.

De modo que, por ahora sí, el profesional de la arqueología es, lo quiera o no, un agente patrimonializador, y además debe seguir siéndolo.

\section{Notas}

2. Celebrado los días 7-9/05/2014. https://ehutb.ehu.es/es/video/index/uuid/537f9f0ad8ee9.html desde minuto 34:13. En esta sesión tomaron parte como ponentes, entre otros Álvaro Falquina Aparicio y Rafael Millán Pascual y la recomiendo vivamente.

3. Weber diferencia las normas legales de las convenciones sociales porque en éstas faltan los especialistas encargados de hacer cumplir las leyes (Miller 2009: 39, nota 20).

4. Davallon (2010: 42 -43, en Sánchez Carretero 2012:197) denomina sustancialistas a los defensores de que "la naturaleza patrimonial de los objetos que llamamos patrimonio es una de sus cualidades intrínsecas". No es eso lo que propugnan nuestras leyes, que fían todo el engranaje de la catalogación a estudios orientados a demostrar el valor patrimonial que, en ningún caso, es preexistente.

5. Ortíz 2015: 396.

6. A este respecto Rodríguez Temiño (2009: 113) indica: "me parece fuera de toda duda que tal documentación deba estar custodiada por administraciones públicas y al servicio de quienes lo soliciten, en las misma condiciones en que se facilita el acceso para su estudio a los bienes muebles recuperados en la intervención arqueológica". No podía estar más de acuerdo.

7. Uno de los máximos responsables de la redacción de la Ley fue Manuel Fernandez Miranda, Catedrático de Prehistoria de la Universidad Complutense, Subdirector General de Arqueología (1979-1982) y Director General de Bellas Artes (1982-84) del Ministerio de Cultura. 
8. Los objetos arqueológicos están fuera del mercado, pero se debe estimar su valoración económica cuando, por ejemplo, un juzgado, ante un expolio, reclama de la administración cultural que lo tase para decidir que pena imponer.

9. En la edición de Taurus de 1973 de las Tesis de filosofia de la Historia incluidas en Los discursos interrumpidos (1994: 182), el traductor y prologuista, Jesús Aguirre, después duque de Alba consorte, la traduce por "servidumbre anónima". Mi desconocimiento del alemán me hacen decantarme, sin motivos razonables, por la más visceral, aunque reconozco el mayor valor literario de esta otra.

10. Un ejemplo turbador de esto es la novela de ciencia ficción "Los cronolitos" de Robert C. Wilson, donde unos descomunales monumentos, que dan título al libro, "aparecen" desde el futuro para "conmemorar" las victorias de un genio militar por llegar. Este patrimonio monumental, efecto de una causa por venir, fomenta la creencia en que esta será inevitable y prepara el camino para su llegada triunfal. De manera que este mesías no se anuncia por la palabra prometedora de destinos manifiestos de tantas religiones, sino por los hechos demostrados (las batallas futuras) que se "rememoran" en los monumentos a mayor gloria del militar. Esta memoria profética se transforma en una especie de patrimonio del porvenir, que predispone a la sociedad a un destino incontestable, desechando cualquier posible alternativa.

11. Concepto acuñado por Laurajane Smith (2006) con el cual describe el discurso hegemónico que subyace en la elección del patrimonio valorado. Pretende conocer, desde un punto de vista antropológico, como surge y como funciona el patrimonio.

12. Las manifestaciones de duelo (por el $11 \mathrm{~S}$, el $11 \mathrm{M}$, Steve Jobs, Charlie Hebdo), las tumbas de personajes insignes (Machado, Jim Morrison, Cesar Augusto), los memoriales de famosos (Camarón, Rocío Jurado,...), algunas fiestas (las Cruces de Granada, los Sanfermines, la cabalgata de los reyes magos, la romería del Rocío, la feria de Sevilla), algunas celebraciones deportivas (la Champion, la copa del Rey) e, incluso, ¿porqué no? la noche estrellada de Teruel, el discurso de navidad del rey o la dieta mediterránea.

13. En esta relación he seguido la laudatio que Mussolini mandó colocar en el frontispicio del hermoso Colosseo Quadrato, y que expresa lo que, para los fascistas, Italia había dado a la civilización, como rememora el nombre oficial del edificio Palazzo della Civiltà Italiana: "Un popolo di poeti, di artisti, di eroi, di santi, di pensatori, di scienziati, di navigatori, di trasmigratori".

14. Fragmento del Manifiesto de Gothenburg (2012) de la Association of Critical Heritage Studies: "Nationalism, imperialism, colonialism, cultural elitism, Western triumphalism, social exclusion based on class and ethnicity, and the fetishising of expert knowledge have all exerted strong influences on how heritage is used, defined and managed". (http://archanth.anu.edu.au/heritage-museum-studies/association-critical-heritage-studies, consultado el 26/01/2016).

15. Sin reparar que, ante el hallazgo de cualquier inmueble arqueológico, y antes de estimar el valor de conservación, se deben realizar investigaciones científicas que doten de contexto arqueológico a lo hallado, y se le proporcione protección mediante decretos ad hoc.

16. Relación de los lieux de mémoire de Pierre Nora.

17. www.elmundo.es/elmundo/2013/02/24/andalucia/1361731127.html.

18. Mi papel de técnico en la escala base de la administración no me capacita para considerarme parte de los "aparatos del Estado", aunque comprendo que haya quién me vea así, por formar parte de los "especialistas encargados de hacer cumplir las leyes". Considero que forman parte de dichos "aparatos", más bien, quienes dominan las instancias decisorias, donde se fijan las políticas públicas o se resuelve excluirlas de los presupuestos, como ocurre últimamente.

\section{Bibliografía}

Alegre Ávila, J.M. (1994): Evolución y régimen jurídico del patrimonio histórico. Vol. 2. Ministerio de Cultura. Madrid.

Barcelona Llop, J. (2000): "El dominio Público arqueológico". Revista de administración pública $\mathrm{N}^{\circ} 151$ : 133-165.

Barreiro Martínez, D. (2012): “Arqueología aplicada y patrimonio: memoria y utopía”. Complutum, No 23, 2: $33-50$.

- (2013): Arqueológicas: hacia una arqueología aplicada. Bellaterra. Barcelona.

Bate, L.F. (1998): El proceso de investigación en arqueología. Crítica. Barcelona.

Benjamin, W. (1971): Angelus Novus. Edhasa. Barcelona.

- (1994): Discursos interrumpidos. Planeta-De Agostini. Barcelona. 
Cabello, F. (1998): “La protección penal del patrimonio arqueológico. Algunos ejemplos ibéricos”. Revista de Estudios Ibéricos, 3.

Cabeza, Á.; Simonetti, S. (Compiladores) 1997: Cartas internacionales sobre patrimonio cultural. Cuadernos del Consejo de Monumentos Nacionales. Segunda serie, $N^{\circ} 21$, Ministerio de Educación de la República de Chile.

Criado Boado, F. (1996): "Hacia un modelo integrado de investigación y gestión del patrimonio histórico: la cadena interpretativa como propuesta". Boletín del Instituto Andaluz del patrimonio histórico. Vol. 16: 73-78.

- (2001): "La Memoria y su huella. Sobre arqueología, patrimonio e identidad". Claves de razón crítica $\mathrm{n}^{\mathrm{o}}$ 115: 36-43.

- (2012): Arqueológicas. La razón perdida. Ediciones Bellaterra. Barcelona.

- (2013): "El patrimonio era otra cosa". Estudios Atacameños, no 45: 5-18.

Davallon, J. (2010): "The game of heritagization". En X. Roigé \& J. Frigolé (eds.): Constructing Cultural and Natural Heritage. Parks, Museums and Rural Heritage. ICRP. Girona: 39-62.

Deleuze, G. (1980): Diálogos Gilles Deleuze / Claire Parnet. Pre-Textos. Valencia.

Foucault, M. (1992): Genealogía del racismo. De la guerra de razas al racismo de Estado. Ediciones la Piqueta. Madrid.

- ([1966] 1999): Las palabras y las cosas. Siglo XXI Editores S.A. $28^{\text {a }}$ edición en español. Madrid.

García-Moreno, A. E.; Rosa-Jiménez, C. y Márquez-Ballesteros, M.J. (2016): "Lo banal como patrimonio de la Costa del Sol. Torremolinos (1959-1979)". Pasos, Revista de Turismo y patrimonio Cultural, Vol. 14, $\mathrm{N}^{\mathrm{o}} 1: 253-273$.

Giovannetti, M.; Páez, M.C. (2009): "El tráfico de objetos arqueológicos en los tiempos modernos. Discusiones y críticas en torno al mercado". Cuba Arqueológica. Volumen 2, № 2: 90 - 102.

González Ruibal, A. (2009): “Arqueología y Memoria Histórica”. Patrimonio cultural de España, №. 1: 103-122.

Lull, V. (1988): "Hacia una teoría de la representación en arqueología". Revista de Occidente no 81: 62-76.

Miller Moya, L.M. (2009): "La noción de convención social. Una aproximación analítica". Papers, 91: 29-43.

Moreu Ballonga, J.L. (2013): La ocupación explicada con ejemplos. Editorial Reus. Madrid.

Nora, P. (1984): Entre mémoire et histoire. Le problematique de les lieux. En Pierre Nora (dir.) Les Lieux de Mémoire, 1: La République. París, Galimard.

Ortiz Sánchez, M. (2015): “Análisis de la jurisprudencia en materias de competencia de la Comunidad Autónoma de Andalucía (continuación)”. En Ma. Dolores Pérez y Miguel Sánchez (coord.) Manual sobre responsabilidad patrimonial de la Administración Pública. Instituto Andaluz de Administración Pública, Sevilla.

Rodríguez Temiño, I. (2009): "Notas sobre la regulación de las actividades arqueológicas". Patrimonio Cultural y Derecho, $\mathrm{n}^{\circ}$ 13: 87-115.

Sánchez-Carretero, C. (2012): "Hacia una antropología del conflicto aplicada al patrimonio", en Santamarina, B. (ed.): Geoolíticas patrimoniales: de culturas, naturalezas e inmaterialidades. Una mirada etnográfica. Editorial Germania. Valencia: 195-210.

Smith, L. (2006): Uses of Heritage. Routledge. New York.

Soler Segura, J. (2007): "Redefiniendo el registro material. Implicaciones recientes desde la arqueología del paisaje anglosajona". Trabajos de Prehistoria 64, N 1: 41-64.

Vicent García, J. (2007): "La arqueología a comienzos del siglo XXI: ciencia, tecnología, valores y sociedad". XII Jornadas de Estudios sobre Lanzarote y Fuerteventura: celebradas en Arrecife, Lanzarote, del 26 al 30 de septiembre de 2005.

Zafra de la Torre, N. (1996): "Hacia una metodología para el estudio del patrimonio arqueológico". Complutum Extra, 6, 2, 1996. Homenaje al profesor Manuel Fernández-Miranda II: 225 - 239

- (2004): "Nombrar, apropiar: arqueología del paisaje y toponimia en la aldea de Otíñar (Jaén) (1300-2000 DNE)". Arqueología y Territorio Medieval 11, 1.

Zinn, H. (2011): La otra historia de los Estados Unidos (desde 1942 hasta hoy). Siete cuentos editorial, New York. 